\title{
The effect of broadening the definition of generalized anxiety disorder on healthcare resource utilization and related costs in outpatient psychiatric clinics
}

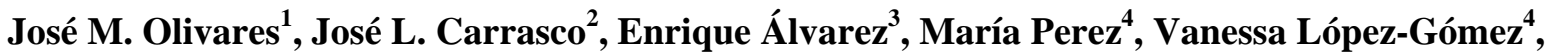 \\ Javier Rejas ${ }^{5}$ \\ ${ }^{1}$ Department of Psychiatry, Hospital Meixoeiro, Complejo Hospitalario Universitario, Vigo, Spain \\ ${ }^{2}$ Department of Psychiatry, Instituto de Investigación Sanitaria, Hospital Clínico San Carlos, Centro de Investigación Biomédica En \\ Red de SAlud Mental (CIBERSAM), Madrid, Spain \\ ${ }^{3}$ Department of Psychiatry, Hospital de la Santa Creu i San Pau, Universitat Autónoma de Barcelona, Centro de Investigación \\ Biomédica En Red de SAlud Mental (CIBERSAM), Barcelona, Spain \\ ${ }^{4}$ Medical Unit, Pfizer, S.L.U., Madrid, Spain \\ ${ }^{5}$ Health Economics and Outcomes Research Department, Pfizer, S.L.U., Madrid, Spain \\ Email: jose.manuel.olivares@gmail.com
}

Received 11 December 2012; revised 13 January 2013; accepted 21 January 2013

\section{ABSTRACT}

Background: Patients with generalized anxiety disorder (GAD) are among the highest users of healthcare resources. The broadening of the DSM-IV criteria for GAD has been a subject of controversy in the literature, but its consequences have not been analyzed to date. Objective: The purpose of this study was to analyze how the broadening of the DSM-IV criteria affects healthcare resource utilization and related costs. Methods: A multicentre, prospective, observational study was conducted in randomly selected outpatient psychiatric clinics between October 2007 and April 2008. Patients diagnosed according to DSM-IV or broader criteria (1 month of excessive or non-excessive worry and only 2 associated DSM-IV symptoms) for the first time were consecutively enrolled. Socio-demographic data, healthcare resources and corresponding costs were collected over a 6month period. Results: A total of 3549 patients were systematically recruited, 1815 in the DSM-IV criteria group (DG) and 1264 in the broad criteria group (BG). Treatments prescribed were similar for antidepressants in both groups $\mathbf{7 7 . 0 \%}$ in the DG vs. $75.3 \%$ in the BG, $p=0.284$ ), and slightly higher in the DG for benzodiazepines $(71.5 \%$ vs. $67.2 \%$ respecttively, $\mathrm{p}=0.011)$ and anticonvulsants $(72.1 \%$ vs. $67.0 \%$ respectively, $p=0.002$ ). Healthcare resource utilization was statistically reduced to a similar extent in both groups as a consequence of treatment, yielding a reduction in the cost of illness of $€ 1196$ (SD = 1158) and $€ 1112(S D=874)$ respectively; $p=0.304$, over a 6-month period. Conclusion: The broadening of the GAD criteria could lead to earlier diagnosis not necessarily associated with an increase in healthcare resource utilization or costs to the National Health System in the six-month follow-up.

Keywords: Generalized Anxiety Disorder; Diagnosis; DSM-IV Criteria; Healthcare Resource Utilization; Costs

\section{INTRODUCTION}

Anxiety disorders are among the most common psychiatric disorders, and generalized anxiety disorder (GAD) is one of the most common [1]. Lifetime prevalence of GAD was estimated to be $2.8 \%$ in Europe and $5.7 \%$ in the United States [1,2]. In a clinical setting, GAD prevalence has been estimated at $7.3 \%$ of patients in primary care and up to $13 \%$ in psychiatric outpatient clinics $[3,4]$. The main feature of GAD is pathological worry, which is accompanied by a variety of somatic and psychological symptoms such as restlessness, muscle tension, sleep disturbance, irritability, difficulty concentrating and fatigue [5]. Given the chronic course of GAD and its low remission rates, normal functioning in these patients is substantially impaired [6]. In fact, GAD patients have lower perceived quality of life than non-anxious controls and a lower level of social functioning than patients with arthritis or diabetes [7].

The persistent nature of GAD makes this condition a considerably impairing anxiety disorder, which results in high use of healthcare resources [8]. This is even higher than in patients with other conditions such as obsessive-compulsive disorder and panic disorder patients [9]. GAD patients do not use healthcare resources for anxiety alone, but are also more likely to seek treatment for other somatic illnesses, pain and sleep disturbances [10]. Furthermore, GAD is associated with a high rate of psychi- 
atric co-morbidity. In this regard, recent studies have suggested that management of both GAD and its comorbidities is the cost driver in GAD [11].

GAD diagnostic criteria have been revised in each edition of the Diagnostic and Statistical Manual of Mental Disorders (DSM) $[5,12,13]$, and the DSM-V is not expected to be an exception [14-16]. Several groups are conducting studies to assess the consequences of broadening the DSM-IV criteria for GAD prevalence, symptom severity, patient impairment and comorbidity [1725]. Although the scientific literature has plenty of economic studies on anxiety disorders, none of those studies have yet evaluated the economic consequences of broadening the DSM-IV criteria for GAD on healthcare resource utilization and costs. The ADAN (Amplification of Definition of Anxiety) study has demonstrated that patients diagnosed using broad GAD criteria respond to treatment similarly to patients diagnosed using the DSMIV when managed at the psychiatrist level [26]. These results suggest that broadening the GAD criteria could lead to earlier diagnosis, which will benefit patients by starting appropriate treatment sooner. This could also translate to improved patient functioning and quality of life. Thus, the goal of the present study - which was a secondary objective of the ADAN trial-was to determine the longitudinal consequences of broadening the DSM-IV criteria for GAD on prospective utilization of healthcare resources and the corresponding costs in newly diagnosed patients [27]. Healthcare resource utilization in the six months prior to the study was compared with utilization during the study in each study group.

\section{METHOD}

\subsection{Study Design}

The ADAN study was a multicentre, prospective, observational study conducted in 618 Spanish outpatient psychiatric clinics between October 2007 and April 2008 [26]. In brief, the study was approved by the local ethics committee of Hospital Clínico de San Carlos (Madrid) and was conducted according to the Declaration of Helsinki regarding biomedical research involving human subjects. Patients or their caregivers were asked to give written informed consent before taking part in the study.

Patients attended outpatient psychiatric clinic three times: Baseline, 3 and 6 month visits. The Hamilton Anxiety Rating Scale [27] was administered at all three visits. Socio-demographic data were collected at the baseline visit. For the healthcare cost analysis, data on current therapy including symptomatic treatments, and psychiatric and medical illnesses were collected both at baseline and at the 6 month visit. At the 3 month visit, psychiatrists collected data related to patient follow-up and current treatments. Participation in the study did not affect the routine clinical practice of the participating physicians. Psychiatrists participating in the study were asked to consecutive select patients newly diagnosed with GAD using the Mini-International Neuropsychiatric Interview (MINI) to verify both the DSM-IV criteria and the abridged criteria as described below.

\subsection{Study Sample}

Eligible patients were men and women over 18 years of age at the time of the baseline visit. Exclusion criteria were patients with a previous diagnosis of GAD, a score $<9$ on the validated Spanish language version of the Hamilton Anxiety Rating Scale (HAM-A) [27], a score $>35$ on the Montgomery-Asberg Depression Rating Scale (MADRS) [27], and inability or difficulty understanding patient-reported outcomes questionnaires written in Spanish (e.g., non-Spanish speakers and illiterate individuals). Diagnosis was made in an outpatient setting by an experienced psychiatrist in practice for at least 5 years, familiar with study procedures. The MINI interview was administered.

A stratified, multistage probability sample was drawn with no replacement of dropouts. The sampling frame included all public and private health systems within the 17 regions of Spain. The first stage consisted of selection of outpatient psychiatric clinics (mental health centres) in each health region. The number of clinics selected in each region was proportional to the population of the region, and the probability of choosing each clinic was relative to the population in the area served by the clinic. In the second stage, one psychiatrist per clinic was chosen at random from among those with previous experience in clinical and epidemiological research in psychiatry and at least 5 years of experience in the diagnosis of mental illness. If a selected psychiatrist refused to participate, he or she was replaced by another one from the same clinic (also selected at random). Finally, in the third stage, patients were selected with a systematic sampling strategy. Participating psychiatrists were asked to invite consecutive patients from the daily list of appointments who met the inclusion and exclusion criteria until the predetermined sample size was achieved.

Sample size was calculated taking into account the study's main variable: progression of anxiety symptoms according to the total HAM-A scores in each patient group. It was estimated that a sample of at least 2500 (1250 per group) evaluable patients was necessary, assuming a 2-tailed 95\% confidence interval (CI) for the total HAM-A scores greater than 0.25 points from the observed mean difference between the two interventions. Based on previous study results, a standard deviation lower than 8 points was assumed [3].

\subsection{Diagnostic Assessments}

GAD was diagnosed using the MINI interview to verify 
DSM-IV criteria in one group (the DSM-IV criteria group, DG) in one group [5]. The other group (the broad criteria group, BG) was diagnosed according to broad criteria consisting of shortening of the anxiety duration from "at least 6 months" to "at least 1 month" and reducing the number of associated symptoms from 3 to 2, according to Ruscio et al. [20]. As described previously, patients were diagnosed by an experienced psychiatrist. Progression of GAD symptoms was assessed with a validated Spanish version of the HAM-A scale at every study visit [27].

\subsection{Use of Healthcare Resources and Costs Estimation}

The perspectives of the patient and the Spanish National Health System were chosen for this analysis. Information regarding utilization of healthcare resource (non-drug treatments, medical visits and hospitalizations due to anxiety) during the last 4 weeks was obtained at the baseline and 6 month visits by patient interview and data extraction from medical records. A case report form was designed ad hoc for this study to collect data on healthcare resources and out-of pocket costs. Drug utilization, medical visits and hospitalizations were collected from patient medical records, while non-drug treatments were recorded by patient interview. Diagnostic tests were not recorded since this variable was considered negligible in GAD. Information regarding drug utilization was collected for the 6 months prior to the baseline visit and the 6 month study visit. Patients were also interviewed about the impact of anxiety symptoms on other costs not covered by the Spanish National Health System (out-ofpocket costs) including medical transportation, caregivers, etc., during the last month. Costs were then extrapolated to a period of 6 months.

Calculations of total cost per patient (in euros, year 2009) included direct costs, which consisted of the sum of healthcare costs and out-of-pocket costs during a period of 6 months before (collected at baseline visit) and after (collected at the 6 month visit) enrolment in the study. Drug costs were obtained from the National Pharmacies Catalogue for the year 2009, using retail prices + VAT of the least expensive generic medications available, or the least expensive proprietary drugs when a generic medication or a reference price was unavailable [28]. Costs of non-drug treatments, medical visits, and hospitalizations were obtained from the eSALUD healthcare costs database for the year 2009, updated with the 2008 inflation rate [29].

\subsection{Statistical Analysis}

Only patients who met all the inclusion criteria and none of the exclusion criteria were included in the statistical analyses. Descriptive statistics were extracted for the continuous variables in the study, including the measure of central tendency and dispersion, with a 95\% CI when possible. A Kolmogorov-Smirnov test was used to check the Gaussian distribution. For categorical variables, absolute and relative frequencies were calculated. For comparisons, Student's t tests and chi-square tests were used for continuous and categorical variables, respectively. Analyses of Covariance (ANCOVA) or binary logistic regression models were fitted comparing DSMIV criteria versus broad criteria groups, adjusting for baseline scoring, socio-demographic variables and comorbidities at enrolment in the study. All types of health resource utilization (number of drugs, non-drug treatments, medical visits and hospitalizations) together with costs (total and by different components), which were considered continuous variables, were analyzed with ANCOVA models as mentioned. Continuous variables were also scored using the HAM-A, MADRS and Clinical Global Impressions-Severity of Illness (CGI-S) scales, which were compared with the baseline visit using a Student's t test. All categorical variables expressed as a percentage (socio-demographic data, type of symptom and co-morbidities) were compared with the baseline visit using a chi-square test.

A multivariate linear regression model was also fitted to explore for possible predictive factors for the change in total direct costs between the 6 months prior to the start of the study and the 6 months after the start of the study. All variables with p-values $<0.2$ in the Pearson's correlation coefficient with a change in total direct costs at the end of the study were included in the model, along with variables having a possible clinical interpretation [26]. A forward stepwise procedure was used and a Wald statistic p-value $<0.05$ was used as a criterion for retaining variables in the model.

All statistical tests were two-tailed, and an $\alpha$ error of $<0.05$ was accepted as statistically significant. Cohen's $\mathrm{d}$ effect size-(ES) was computed as a measurement of clinical relevance by dividing differences between groups by the pooled baseline standard deviation value when the comparison reached statistical significance [30]. Data were analyzed using SAS statistical software, version 8.2.

\section{RESULTS}

In this observational study, a total of 618 Spanish psychiatrists recruited 3549 patients to participate in the study, 453 of whom (12.8\%) were excluded because they did not meet the inclusion criteria; $334(9.4 \%)$ with a score $>35$ on the MADRS scale, $54(1.5 \%)$ with a score $<9$ on the HAM-A scale, $42(1.2 \%)$ patients not newly diagnosed with GAD, $24(0.7 \%)$ unable to understand questionnaires written in Spanish, $5(0.1 \%)$ did not pro- 
vide written consent and 1 under 18 years of age. Enrolled patients were diagnosed according to DSM-IV criteria (1815 patients) or broad criteria (1264 patients). The main patient socio-demographic characteristics are shown in Table 1. As expected, statistically significant

Table 1. Baseline characteristics of study subjects by criteria group (mean $\pm \mathrm{SD})$.

\begin{tabular}{|c|c|c|c|}
\hline & $\begin{array}{c}\text { DSM-IV } \\
\text { criteria }(\mathrm{n}=1815)\end{array}$ & $\begin{array}{l}\text { Abridged } \\
\text { iteria }(\mathrm{n}=1264)\end{array}$ & $\mathrm{p}$ \\
\hline Gender (Female) (\%) & $1145(68.1 \%)$ & $748(64.2 \%)$ & 0.029 \\
\hline Age (years) & $45.5 \pm 13.0$ & $42.9 \pm 13.2$ & $<0.001$ \\
\hline BMI $\left(\mathrm{Kg} / \mathrm{m}^{2}\right)$ & $25.4 \pm 4.2$ & $24.7 \pm 3.8$ & $<0.001$ \\
\hline Obesity $\%(N)^{\S}$ & $10.9(184)$ & $7.0(82)$ & $<0.001$ \\
\hline \multicolumn{4}{|l|}{$\begin{array}{c}\text { Highest educational } \\
\text { level } \%(\mathrm{~N})\end{array}$} \\
\hline No studies & $4.2(75)$ & $3.1(40)$ & 0.167 \\
\hline Elementary school & $55.6(1008)$ & $44.6(562)$ & $<0.001$ \\
\hline High school & $19.9(361)$ & $25.2(317)$ & 0.001 \\
\hline College or higher & $19.5(354)$ & $26.2(330)$ & $<0.001$ \\
\hline \multicolumn{4}{|l|}{ Employment status \% (N) } \\
\hline Employed & $52.5(952)$ & $59.2(747)$ & 0.001 \\
\hline Unemployed & $7.6(138)$ & $7.5(94)$ & 0.868 \\
\hline Housewife & $22.6(409)$ & $16.7(211)$ & $<0.001$ \\
\hline Other & $17.3(313)$ & $16.6(209)$ & 0.612 \\
\hline \multicolumn{4}{|l|}{ Marital status \% (N) } \\
\hline Single & $23.6(428)$ & $29.0(366)$ & 0.001 \\
\hline Married/Living together & $61.9(1,121)$ & $58.4(736)$ & 0.049 \\
\hline Divorced & $9.9(179)$ & $9.4(118)$ & 0.627 \\
\hline Widowed & $4.6(83)$ & $3.3(41)$ & 0.065 \\
\hline $\begin{array}{l}\text { Mean number of GAD } \\
\text { symptoms }\end{array}$ & $4.7 \pm 1.0$ & $4.3 \pm 1.2$ & $<0.001$ \\
\hline \multicolumn{4}{|l|}{ Symptoms \% (N) } \\
\hline Restlessness & $90.0(1504)$ & $86.3(977)$ & 0.003 \\
\hline Being easily fatigued & $63.7(1065)$ & $52.2(591)$ & $<0.001$ \\
\hline Difficulty concentrating & $80.8(1351)$ & $75.3(852)$ & 0.001 \\
\hline Irritability & $77.4(1293)$ & $71.2(806)$ & $<0.001$ \\
\hline Muscle tension & $77.8(1300)$ & $71.0(804)$ & $<0.001$ \\
\hline Sleep disturbance & $84.6(1414)$ & $76.5(866)$ & $<0.001$ \\
\hline \multicolumn{4}{|l|}{ HAM-A } \\
\hline Total scale score & $26.0 \pm 7.0$ & $24.4 \pm 7.2$ & 0.001 \\
\hline Psychic anxiety sub-score & $14.5 \pm 3.6$ & $13.7 \pm 3.7$ & $<0.001$ \\
\hline Somatic anxiety sub-score & $11.5 \pm 4.3$ & $10.7 \pm 4.4$ & 0.008 \\
\hline MADRS & $22.4 \pm 6.9$ & $21.3 \pm 7.1$ & 0.001 \\
\hline CGI-S & $4.1 \pm 0.8$ & $4.0 \pm 0.8$ & 0.002 \\
\hline
\end{tabular}

$\S$ Obesity defined as BMI $>30 \mathrm{Kg} / \mathrm{m}^{2}$; HAM-A = Hamilton Rating Scale for Anxiety; MADRS = Montgomery-Asberg Depression Rating Scale; CGI-S $=$ Clinical Global Impression-Severity of Illness Scale. There were no large effect size in mean differences $(<0.25$ in all cases, except for mean number of GAD symptoms; 0.33). between group differences were observed in anxiety symptoms per the HAM-A score, with a mean (standard deviation) total score of 26.0 (7.0) versus 24.4 (7.2), respectively; $p=0.001$. However, these difference were not or were only barely clinically relevant $(\mathrm{ES}<0.25$ in cases with statistically significant differences), with the exception of obesity prevalence (higher in the DSM-IV group; $10.9 \%$ versus $7.0 \%, \mathrm{p}<0.001$ ). Furthermore, patients in the DG had a somewhat lower educational status and employment rate than patients with BG. Differences observed in symptoms scale scores had no large effect size (Table 1), although they were statistically different as mentioned previously. The mean MADRS scale score was statistically significant ( $p=0.001$, Table 1 ), although the magnitude of the difference was small: 22.4 (6.9) versus 21.3 (7.1), $\mathrm{ES}<0.25$. GAD symptoms were more prevalent and severe in the DSM-IV group by definition, but the magnitude of difference was small (Table 1) as ES values were $<0.25$ in all cases, except for mean number of GAD symptoms, which was 0.33 .

At enrolment in the study, patients who had at least one psychiatric co-morbidity were $51.4 \%$ in the DG and $43.7 \%$ in the BG $(p<0.001)$. The most common psychiatric conditions and medical disorders in the two study groups are shown in Table 2. Major depression was the condition most often found as a co-morbidity in the two groups; $31.8 \%$ versus $27.2 \%(p=0.071)$, followed by concomitant panic disorder; $19.3 \%$ versus $19.6 \%, \mathrm{p}=$ 0.931 . Neither the mean number of co-morbid psychiatric disorders nor the medical illnesses was different in the two criteria groups $(p=0.369$ and $p=0.282$, respectively). Most psychiatric disorders were present for about 5 months before the diagnosis of GAD, with no significant differences between groups in disease course. Of the concomitant medical illnesses, chronic pain was present in more than half of patients in both groups, with a higher percentage in the DG; $64.3 \%$ versus $52.0 \%$, p < 0.001 (Table 2).

In the 6 months prior to the study, drug treatment was prescribed in more than $80 \%$ of patients in both groups ( $87.9 \%$ in the DG; $82.0 \%$ in the BG, Figure 1), benzodiazepines being the most commonly used among all participants (89.4\% and $88.5 \%$, respectively, $p=0.443)$, but with significant differences, as expected, in the frequency of antidepressants $(69.6 \%$ and $59.2 \%$, respectively, $\mathrm{p}<0.001)$ and antiepileptics $(22.4 \%$ and $17.5 \%$, respectively, $\mathrm{p}=0.002$ ), The percentage of treated patients increased to $97 \%$ by the end of the study. The most notable change was an increase in the prescription of antiepileptics from $22.4 \%$ to $72.1 \%$ in the DG, and from $17.5 \%$ to $67.0 \%$ in the $\mathrm{BG}(\mathrm{p}<0.01$ in both cases versus baseline), this being significantly higher in the DG $(p<0.01$, Figure 1).

The results for healthcare resource utilization during the study period are shown in Table 3, while costs are 
Table 2. Most frequent co-morbid psychiatric disorders and medical illnesses at baseline visit by criteria group.

\begin{tabular}{|c|c|c|c|c|}
\hline & \multicolumn{2}{|c|}{ DSM-IV criteria } & \multicolumn{2}{|c|}{ Abridged criteria } \\
\hline \multicolumn{5}{|c|}{ Co-morbid psychiatric disorders } \\
\hline & $\begin{array}{c}\text { Frequency, } \\
\%(\mathrm{~N})\end{array}$ & $\begin{array}{c}\text { Time } \\
(\text { months }) \\
(\text { mean } \pm \text { SD) }\end{array}$ & $\begin{array}{l}\text { Frequency, } \\
\%(\mathrm{~N})\end{array}$ & $\begin{array}{c}\text { Time } \\
\text { (months) } \\
(\text { mean } \pm \mathrm{SD})\end{array}$ \\
\hline Major depression & $31.8(294)$ & $5.5 \pm 6.1$ & $27.2(150)$ & $6.2 \pm 7.9$ \\
\hline Panic disorders & $19.3(178)$ & $4.0 \pm 4.2$ & $19.6(108)$ & $3.0 \pm 3.8$ \\
\hline Social phobia & $14.9(138)$ & $4.6 \pm 5.2$ & $16.5(91)$ & $3.3 \pm 4.6$ \\
\hline Phobias & $13.5(125)$ & $4.9 \pm 6.1$ & $14.1(78)$ & $4.6 \pm 5.6$ \\
\hline $\begin{array}{l}\text { Other depressive } \\
\text { disorders }^{1}\end{array}$ & $11.9(110)$ & $5.8 \pm 5.2$ & $10.3(57)$ & $5.2 \pm 4.2$ \\
\hline $\begin{array}{l}\text { Obsessive } \\
\text { compulsive } \\
\text { disorder }\end{array}$ & $6.3(59)$ & $7.4 \pm 7.1$ & $6.7(37)$ & $8.5 \pm 7.4$ \\
\hline Substance abuse & $5.5(51)$ & $4.6 \pm 5.1$ & $4.3(24)$ & $5.7 \pm 5.5$ \\
\hline $\begin{array}{c}\text { Adjustment } \\
\text { disorders }\end{array}$ & $3.6(34)$ & $2.8 \pm 3.3$ & $5.2(29)$ & $1.9 \pm 2.7$ \\
\hline $\begin{array}{l}\text { Mean (SD) } \\
\text { number of } \\
\text { disorders }\end{array}$ & \multicolumn{2}{|c|}{$1.2(0.5)$} & \multicolumn{2}{|c|}{$1.2(0.5)$} \\
\hline \multicolumn{5}{|c|}{ Co-morbid medical illnesses } \\
\hline $\begin{array}{c}\text { Mean (SD) } \\
\text { number of } \\
\text { illnesses }\end{array}$ & \multicolumn{2}{|c|}{$1.5(0.9)$} & \multicolumn{2}{|c|}{$1.5(0.8)$} \\
\hline Chronic pain, $\%$ (n) & \multicolumn{2}{|c|}{$64.3(735)^{\ddagger}$} & \multicolumn{2}{|c|}{$52.0(343)$} \\
\hline $\begin{array}{l}\text { Gastrointestinal } \\
\text { diseases, \% (n) }\end{array}$ & \multicolumn{2}{|c|}{$29.1(333)$} & \multicolumn{2}{|c|}{$29.7(196)$} \\
\hline $\begin{array}{l}\text { Cardiovascular } \\
\text { diseases, \% (n) }\end{array}$ & \multicolumn{2}{|c|}{$15.0(172)$} & \multicolumn{2}{|c|}{$17.6(116)$} \\
\hline $\begin{array}{c}\text { Metabolic } \\
\text { diseases, \% (n) }\end{array}$ & \multicolumn{2}{|c|}{$10.9(125)$} & \multicolumn{2}{|c|}{$12.1(80)$} \\
\hline $\begin{array}{l}\text { Genitourinary tract } \\
\text { diseases, } \%(n)\end{array}$ & \multicolumn{2}{|c|}{$7.3(84)$} & \multicolumn{2}{|c|}{$6.5(43)$} \\
\hline Muscular pain, $\%$ (n) & \multicolumn{2}{|c|}{$3.1(35)$} & \multicolumn{2}{|c|}{$2.9(19)$} \\
\hline
\end{tabular}

$\mathrm{SD}=$ Standard deviation. Results are shown as percentage of patients in each group presenting with every illness (frequency) and time from diagnosis till baseline visit (in months). ${ }^{1}$ Includes depressive disorders different than major depression, dystimia, combined disorders of anxiety and depression, reactive depression, unspecified depressive disorder, secondary depression to abuse of substances/drugs, etc. ${ }^{\ddagger} \mathrm{p}<0.001$ versus abridged criteria group. Not significant when not indicated.

included in Table 4. A number of patients $(33.3 \%$ in the DG; $25.9 \%$ in the $\mathrm{BG}$ ) were using non-drug treatments to alleviate their anxiety. The most common among these treatments were cognitive-behavioral therapy $(14.8 \%$ and $11.9 \%$, respectively, $\mathrm{p}=0.025$ ) and relaxation techniques $(11.6 \%$ and $10.2 \%$, respectively, $\mathrm{p}=0.224)$. Regarding physician consultations, more than $90 \%$ of patients in both groups visited a physician at least once in the 6 months prior to the study $(91.6 \%$ for the DG and $93.2 \%$ for the BG) and during the study (91.7\% and $93.3 \%$, respectively), but the differences were not statistically significant in either case $(p=0.118$ and $p=0.094$, respectively). Resource utilization in terms of doctor visits also did not differ significantly between the DG and BG at the end of the study $(p=0.397)$. Physician visits decreased during the study period mainly due to a reduction in the

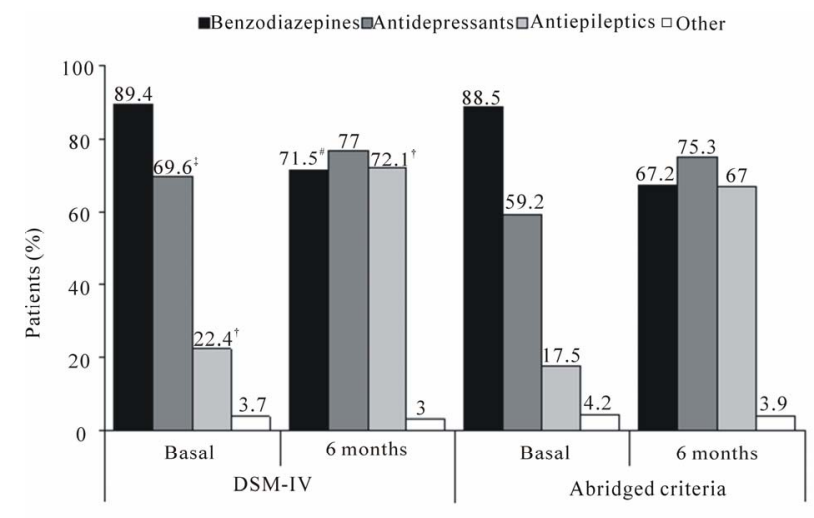

(a)

(b)

Figure 1. Drugs used for GAD treatment at baseline and 6 month visits. (a) DSM-IV criteria group; (b) Abridged criteria group. Data presented as percentage of patients in each group. Differences not significant when not indicated. All changes, except for other, were statistically significant when compared to the baseline visit $\left(\mathrm{p}<0.001\right.$ in all cases). ${ }^{\#} \mathrm{p}<0.05,{ }^{\dagger} \mathrm{p}<0.01$ and ${ }^{\star} \mathrm{p}<0.001$ when comparing DSM-IV and abridged criteria groups in both visits.

number of visits to primary care doctors ( 8 visits approximately at the end of the study in both groups, $\mathrm{p}<$ 0.001 versus baseline, but with no statistical differences between groups, $p=0.108$ ). A low percentage of patients required hospitalization during the 6 months prior to the study $(2.1 \%$ and $1.1 \%$, respectively; $p=0.747)$; this requirement significantly decreased during the study period in both groups; $p<0.001$ versus baseline.

Regarding the total direct costs, there was a significant reduction during the study period in both groups (Table 4). Total direct costs in the 6 months prior to the study were $€ 2016$ for the DG and $€ 1626$ for the BG, and were significantly lower by the end-of-study visit: $€ 488$ and $€ 134$, respectively ( $p<0.01$ in both cases). The healthcare costs also decreased significantly in both groups (by $€ 386$ and $€ 125$, respectively; $p<0.01$ in both cases) during the study compared with the costs in the 6 months prior to the study. These significant reductions were mainly due to a decrease in physician visit costs $(€ 544$ and $€ 467$, respectively; $p<0.001$ in both cases versus baseline, but with no statistical significance in the between-group comparison, $\mathrm{p}=0.703$ ). These reductions offset the significant increase in drug costs observed in both groups; $€ 208$ and $€ 242$, respectively ( $p<0.001$ versus baseline but with no statistical differences between groups, $p=0.831$ ). Likewise, the comparison between the DG and BG in healthcare costs reductions did not reach statistical significance; $p=0.304$ (Table 4).

A multivariate stepwise linear regression analysis was performed to identify possible predictors of change in total healthcare costs in GAD between the previous 6 months and the end of the study (Table 5). The criteria used for diagnosis (DSM-IV or broad criteria) were not 
Table 3. Utilization of healthcare resources at baseline visit compared to the 6 month visit by criteria group.

\begin{tabular}{|c|c|c|c|c|c|}
\hline \multirow{2}{*}{ Resource } & \multicolumn{2}{|c|}{ DSM-IV criteria $(\mathrm{n}=1815)$} & \multicolumn{2}{|c|}{ Abridged criteria $(n=1264)$} & \multirow{2}{*}{$\begin{array}{c}\text { Adjusted change } \\
\text { difference [CI 95\%], }\end{array}$} \\
\hline & Baseline & Change at 6 months & Baseline & Change at 6 months & \\
\hline Number of Drugs & $2.1(1.5)^{* * *}$ & $0.5(1.5)^{\ddagger}$ & $1.7(1.3)$ & $0.8(1.3)^{\ddagger}$ & $0.0[-0.1,0.1], 0.573$ \\
\hline Number of Non-drugs therapies ${ }^{1}$ & $0.4(0.6)^{* * *}$ & $0.2(0.6)^{\dagger}$ & $0.3(0.6)$ & $0.3(0.6)^{\dagger}$ & $-0.0[-0.1,0.0] 0.071$ \\
\hline Physician visits & $22.8(21.5)$ & $-12.6(19.9)^{\ddagger}$ & $21.5(17.9)$ & $-11.7(16.3)^{\ddagger}$ & $-1.3[-2.8,0.3], 0.108$ \\
\hline Primary care & $11.2(12.5)$ & $-7.6(11.5)^{\ddagger}$ & $11.7(11.5)$ & $-8.1(10.6)^{\ddagger}$ & $-0.1[-0.6,0.4], 0.692$ \\
\hline Psychotherapist & $2.9(7.4)^{* *}$ & $-0.9(6.3)^{\S}$ & $2.3(6.6)$ & $-0.4(5.4)^{\S}$ & $-0.1[-0.4,0.3], 0.984$ \\
\hline Psychiatrist & $5.0(7.1)^{* *}$ & $-1.3(6.6)^{\ddagger}$ & $4.0(5.4)$ & $-0.6(5.3)^{\ddagger}$ & $-0.1[-0.1,0.4], 0.348$ \\
\hline Emergency room & $3.7(7.0)$ & $-2.8(6.5)^{\ddagger}$ & $3.4(5.7)$ & $-2.7(5.3)^{\ddagger}$ & $-0.0[-0.2,0.2], 0.984$ \\
\hline Hospitalization & $0.5(8.7)$ & $-0.5(8.7)^{\ddagger}$ & $0.1(0.8)$ & $-0.0(0.7)^{\ddagger}$ & $-0.0[-0.0,0.0], 0.747$ \\
\hline
\end{tabular}

${ }^{1}$ Includes psychosocial therapy, cognitive treatments, psychoanalytic support, physical therapies, etc. Data shown as mean (standard deviation); CI = Confidence interval; ${ }^{\S} \mathrm{p}<0.05,{ }^{\dagger} \mathrm{p}<0.01,{ }^{\dagger} \mathrm{p}<0.001$, not significant vs. baseline visit when not indicated; ${ }^{*} \mathrm{p}<0.05,{ }^{* *} \mathrm{p}<0.01$, ${ }^{* * *} \mathrm{p}<0.001$ between groups comparison. Change difference adjusted by baseline scoring, socio-demographic variables and co morbidities at entry of the study.

Table 4. Healthcare and out-of-pocket average costs associated to GAD during the study time by criteria group.

\begin{tabular}{|c|c|c|c|c|c|}
\hline \multirow{2}{*}{ Costs $(€)$} & \multicolumn{2}{|c|}{ DSM-IV criteria $(\mathrm{n}=1815)$} & \multicolumn{2}{|c|}{ Abridged criteria $(n=1264)$} & \multirow{2}{*}{$\begin{array}{c}\text { Adjusted Change } \\
\text { difference [CI 95\%], }\end{array}$} \\
\hline & Baseline & Change at 6 months & Baseline & Change at 6 months & \\
\hline Out-of-pocket & 435 (1015) & $-102(858)$ & $390(983)$ & $-10(1191)$ & $-79[-153,-5], 0.038$ \\
\hline Healthcare & $1582(2931)^{* * *}$ & $-386(2787)^{\dagger}$ & $1236(1271)$ & $-125(1070)^{\dagger}$ & $+38[-35,+111], 0.304$ \\
\hline Medical visits & $1034(1194)^{* *}$ & $-544(1109)^{\ddagger}$ & $913(943)$ & $-467(876)^{\ddagger}$ & $+8[-35,+52], 0.703$ \\
\hline Hospitalization & $131(2368)$ & $-123(2364)^{\ddagger}$ & $21(205)$ & $-12(183)^{\S}$ & $-1[-10,+7], 0.745$ \\
\hline Non-drug therapies & $208(497)^{* *}$ & $73(540)^{\ddagger}$ & $168(467)$ & $112(484)^{\ddagger}$ & $-22[-59,+15], 0.247$ \\
\hline Drug treatment & $209(320)^{* * *}$ & $208(307)^{\ddagger}$ & $134(238)$ & $242(296)^{\ddagger}$ & $+2[-20,+24], 0.831$ \\
\hline Total direct & $2016(3176)^{* * *}$ & $-488(2935)^{+}$ & $1626(1761)$ & $-134(1682)^{\dagger}$ & $-55[-167,+58], 0.339$ \\
\hline
\end{tabular}

Data shown as mean (standard deviation); $\mathrm{CI}=$ Confidence interval; ${ }^{\S} \mathrm{p}<0.05,{ }^{\dagger} \mathrm{p}<0.01,{ }^{\dagger} \mathrm{p}<0.001$, not significant vs. baseline visit when not indicated; ${ }^{*} \mathrm{p}<$ $0.05,{ }^{* *} \mathrm{p}<0.01,{ }^{* * *} \mathrm{p}<0.001$ between groups comparison. Change difference adjusted by baseline scoring, socio-demographic variables and co morbidities at entry of the study.

Table 5. Significant predictors of healthcare cost variation during the 6 months analysed period.

\begin{tabular}{|c|c|c|c|c|}
\hline Predictors & B-coefficient & Standard error & $\mathrm{t}$ & $\mathrm{p}$ \\
\hline HAM-A psychic anxiety sub-score at baseline & -42.9 & 14.7 & -2.92 & 0.004 \\
\hline EQ-5D baseline score for daily activities & 284.7 & 104.1 & 2.73 & 0.006 \\
\hline Benzodiazepine use in the 6 months previous to the study & -256.2 & 124.0 & -2.07 & 0.039 \\
\hline Antidepressant use in the 6 months previous to the study & -340.8 & 108.0 & -3.16 & 0.002 \\
\hline Antiepileptic use in the 6 months previous to the study & -665.8 & 134.7 & -4.94 & $<0.001$ \\
\hline Non-drug treatment in the 6 months previous to the study & -572.0 & 111.9 & -5.11 & $<0.001$ \\
\hline
\end{tabular}

Adjusted $\mathrm{R}^{2}=0.04$.

statistically associated with cost variation. Previous treatment with antiepileptics, antidepressants, benzodiazepines or non-drug therapies in the 6 months prior to baseline visit was associated with significant decreases in cost variation. Likewise, baseline score on the psychic domain of the HAM-A was negatively associated with change in healthcare costs at the end of study, with the cost variation in 6 months being nearly $€ 43$ lower for 
each point increase in the psychic sub-score of the HAM-A scale. The only predictive factor that showed a positive increase in cost variation was daily activities at baseline, as assessed by the corresponding item of the EQ-5D questionnaire.

\section{DISCUSSION}

The broadening of the GAD diagnostic criteria by shortening the duration of anxiety from 6 to 1 month and reducing the number of associated symptoms from 3 to 2 had no significant effect on healthcare utilization in GAD or the corresponding costs for patients treated in outpatient psychiatric clinics. In follow-ups ranging from 1 to 6 months, the broadening of GAD criteria resulted in significant improvements in patient quality of life by avoiding months of suffering due to delay of appropriate diagnosis and treatment which, in turn, may contribute to breaking the cycle of GAD. Therefore, broadening the GAD criteria would benefit these patients without increasing the associated economic burden.

Healthcare utilization and costs in GAD have been studied previously [9,31-34]. A recent systematic review by Konnopka et al. of the cost of illness in anxiety disorders points out that GAD and panic disorder are the anxiety conditions with the highest direct costs [35]. In this regard, GAD patients reportedly spend up to $€ 971$ in total annual healthcare costs compared to $€ 548$ by the reference group in a primary care setting [33]. Also, three-month total costs for GAD have been estimated to be $€ 954$ without co-morbidity and $€ 1633$ with co-morbidity $[36,37]$. A European study estimated the per-patient cost of GAD at $€ 1804$ annually, which is higher than any other anxiety disorder [9]. Marciniak et al. [31] and Olfson and Gameroff [32] estimated the total annual cost of GAD at \$2464 and median healthcare costs at $\$ 2375$. Unfortunately, the studies mentioned above use different diagnostic criteria (ICD-9, ICD-10, DSM-III-R and DSM-IV), which reduces the comparability of their data with the ones included here. Moreover, all these studies took a retrospective approach using clinical trial populations or database analyses to calculate both healthcare utilization and costs. To the best of our knowledge, ours is the first study to assess the healthcare costs of GAD in a prospective manner, in a real world setting that incorporated the impact of broadening the diagnostic criteria on healthcare resource utilization and costs. The total direct costs observed were $€ 2016$ and $€ 1626$ at baseline, which is somewhat higher than the value observed by Sicras-Mainar also in Spain but in a primary care setting [33]; however, they are within the range of total costs estimated for Europe by Andlin-Sobocki et al. [9]. As mentioned before, a comparison of healthcare costs in two populations diagnosed using different criteria allows us to draw conclusions about the effect of re- vising the DSM-IV criteria from an economic perspective. Other studies assessing the effect of broadening the DSM-IV criteria have shown its effect on prevalence, symptom severity and even on disability [17-23]; however, none have studied the consequences of broadening the criteria on the economic burden of GAD. In this study, total costs were similarly reduced in both criteria groups (by $€ 488$ for the DG and $€ 134$ for the BG), suggesting that broadening the GAD criteria will not translate to greater economic burden (adjusted difference of $€ 55, \mathrm{p}=0.339$ ).

The main driver of direct costs was medical visits in both criteria groups ( $€ 1034$ and $€ 913$ for the DG and BG at baseline, respectively). Primary care visits were significantly reduced in both groups $(-7.6$ and -8.1 , respectively). The fact that patients most likely came from a primary care setting in which they were not successfully treated could explain this reduction in primary care visits, once the patients were adequately managed. An Australian study determined that treating anxiety patients according to standard guidelines reduced direct costs, thus increasing cost-effectiveness compared with current care [38]. At baseline, prior to a formal diagnosis, most patients had already been treated with several first-line treatments (over $80 \%$ in both groups), mostly prescriptions signed by primary care physicians who initiated treatment for anxiety symptoms before a formal diagnosis could be established. This reflects what is happening in the real world of primary care in patients presenting with symptoms of anxiety. Interestingly, at the end of the study, there was a shift in the drugs used, mainly due to an increase in the prescription of antiepileptic drugs, which was associated with a significant increase in the costs associated with drug treatment. This was because patients had already tried other anxiolytic drugs. However, this increase in drug therapies was largely offset by the reduction in physician visits. As in the previously mentioned Australian study, the results suggest that effective GAD management leads to a reduction in total direct costs [38].

Impairment of daily activities was the only predictive factor associated with a cost increase at the end of the study. Thus the healthcare cost at the end of the study increases for every increase in the degree of impairment of daily activities. The other significant predictive factors were severity of anxiety at baseline (measured by the HAM-A psychic anxiety sub-score) and previous treatment for anxiety. In other words, prior therapy with drugs or other medical interventions negatively impacts the cost reduction during the study.

The study is not free of possible limitations. One of them is the observational design of the ADAN study with its inherent limitations. Patients included in this study may not be representative of the whole GAD population 
since they come from outpatient psychiatric clinics, where psychiatrists may be dealing with the most severe and refractory cases [3]. Also, a high proportion of patients were treated with antiepileptics; that may be explained by the fact that most subjects enrolled in the study were non-responders to recommended first-line drug treatment according to the European guidelines on the treatment and management of GAD patients [7,39]. Another possible limitation is related to the method used to collect data on health resource utilization, which was subject to patient memory for some resources, meaning that the analysis both under- and over-estimate actual resource utilization. Finally, in terms of costs, we did not make a distinction between co-morbid and pure GAD; therefore, some of the costs attributed to GAD may be due to the co-morbid disorder, which could mean an over-estimation of the GAD cost.

In summary, despite above limitations, for patients treated at psychiatric facilities, broadening of the GAD criteria by reducing the duration of excessive and non-excessive worry to 1 month and the number of associated symptoms to 2 is associated with a significant reduction in healthcare and out-of pocket costs. These reductions were similar in magnitude to those observed in GAD patients meeting the DSM-IV criteria. Thus, broadening the GAD diagnostic criteria was shown to not greatly influence the response of GAD symptoms to therapy while improving health-related quality of life and reducing disability. Therefore, clinicians and payers should consider shortening the time to fully diagnose a patient with GAD and, then allocating the appropriate therapy to the patient in order to reduce the economic burden of GAD. Greater awareness of the place of GAD in the anxiety continuum and an increased role of psychiatrists in supporting primary care physicians for recognition of GAD, so that appropriate treatment is given early in the disorder, will have the most beneficial effects on our patients in the future.

\section{AUTHOR DISCLOSURE}

Role of Funding Source: This study was funded by Pfizer, S.L.U. All authors had complete access to the data, participated in the analysis and/or interpretation of results, and drafted the manuscript. Editorial support was provided by Soledad Santos and was funded by Pfizer, S.L.U.

Conflict of interest: María Pérez, Vanessa LópezGómez, and Javier Rejas are employed by Pfizer, S.L.U. All other authors declare that they have no conflicts of interests.

Contributors: JMO, JLC, EA, MP, VLG and JR were responsible for the design of the study. Data were analyzed externally with funding provided by Pfizer, S.L.U. $\mathrm{EA}, \mathrm{JLC}, \mathrm{JMO}$ and JR were responsible for the interpre- tation of data. VLG and MP were responsible for the logistics and conduct of the study. All authors participated in manuscript preparation.

\section{REFERENCES}

[1] Alonso, J., Angermeyer, M.C., Bernert, S., Bruffaerts, R., Brugha, T.S., Bryson, H., et al. (2004) Prevalence of mental disorders in Europe: Results from the European study of the epidemiology of mental disorders (ESEMeD) project. Acta Psychiatrica Scandinavica Supplementum, 420, 21-27.

[2] Kessler, R.C., Berglund, P., Demler, O., Jin, R., Merikangas, K.R. and Walters, E.E. (2005) Lifetime prevalence and age-of-onset distributions of DSM-IV disorders in the National Comorbidity Survey Replication. Archives of General Psychiatry, 62, 593-602. doi:10.1001/archpsyc.62.6.593

[3] Caballero, L., Bobes, J., Vilardaga, I. and Rejas, J. (2009) [Clinical prevalence and reason for visit of patients with generalized anxiety disorder seen in the psychiatry outpatient clinics in Spain. Results of the LIGANDO study]. Actas Españolas Psiquiatría, 37, 17-20.

[4] Chocrón Bentata, L., Vilalta Franch, J., Legazpi Rodríguez, I., Auquer, K. and Franch, L. (1995) Prevalence of psychopathology at a primary care center. Atencion Primaria, 6, 586-590,592-593.

[5] American Psychiatric Association (2000) Diagnostic and statistical manual of mental disorders: DSM-IV TR. American Psychiatric Pub, Washington DC.

[6] Kessler, R.C. and Wittchen, H.U. (2002) Patterns and correlates of generalized anxiety disorder in community samples. Journal of Clinical Psychiatry, 63, 4-10.

[7] Katzman, M.A. (2009) Current considerations in the treatment of generalized anxiety disorder. CNS Drugs, 23, 103-120. doi:10.2165/00023210-200923020-00002

[8] McLaughlin, T.P., Khandker, R.K., Kruzikas, D.T. and Tummala, R. (2006) Overlap of anxiety and depression in a managed care population: Prevalence and association with resource utilization. Journal of Clinical Psychiatry, 67, 1187-1193.

[9] Andlin-Sobocki, P. and Wittchen, H.U. (2005) Cost of anxiety disorders in Europe. European Journal of $\mathrm{Neu}$ rology, 12, 39-44. doi:10.1111/j.1468-1331.2005.01196.x

[10] Wittchen, H.U. (2002) Generalized anxiety disorder: Prevalence, burden, and cost to society. Depression and Anxiety, 16, 162-171. doi:10.1002/da.10065

[11] Zhu, B., Zhao, Z., Ye, W., Marciniak, M.D. and Swindle, R. (2009) The cost of comorbid depression and pain for individuals diagnosed with generalized anxiety disorder. Journal of Nervous \& Mental Disease, 197, 136-139. doi:10.1097/NMD.0b013e3181963486

[12] American Psychiatric Association (1980) Diagnostic and statistical manual of mental disorders, DSM-III. American Psychiatic Association, Washington DC.

[13] American Psychiatric Association (1987) Diagnostic and statistical manual of mental disorders, DSM-III-R. American Psychiatric Association, Washington DC. 
[14] Phillips, K.A. (2009) Report of the DSM-V anxiety, obsessive-compulsive spectrum, posttraumatic, and dissociative disorders work group. American Psychiatric Association, Washington DC.

[15] Andrews, G., Hobbs, M.J., Borkovec, T.D., Beesdo, K., Craske, M.G., Heimberg, R.G., Rapee, R.M., Ruscio, A.M. and Stanley, M.A. (2010) Generalized worry disorder: A review of DSM-IV generalized anxiety disorder and options for DSM-V. Depression and Anxiety, 27, 134-147. doi: $10.1002 /$ da. 20658

[16] Lebeau, R.T., Glenn, D.E., Hanover, L.N., Beesdo-Baum, K., Wittchen, H.U. and Craske, M.G. (2012) A dimensional approach to measuring anxiety for DSM-5. International Journal of Methods in Psychiatric Research, 21, 258-272. doi:10.1002/mpr.1369

[17] Angst, J., Gamma, A., Joseph Bienvenu, O., Eaton, W.W., Ajdacic, V., Eich, D. and Rössler W. (2006) Varying temporal criteria for generalized anxiety disorder: Prevalence and clinical characteristics in a young age cohort. Psychological Medicine, 36, 1283-1292. doi:10.1017/S0033291706007938

[18] Kessler, R.C., Brandenburg, N., Lane, M., Roy-Byrne, P., Stang, P.D., Stein, D.J. and Wittchen, H.U. (2005) Rethinking the duration requirement for generalized anxiety disorder: Evidence from the National Comorbidity Survey Replication. Psychological Medicine, 35, 1073-1082. doi:10.1017/S0033291705004538

[19] Lee, S., Tsang, A., Ruscio, A.M., Haro, J.M., Stein, D.J., Alonso, J., et al. (2009) Implications of modifying the duration requirement of generalized anxiety disorder in developed and developing countries. Psychological Medicine, 39, 1163-1176. doi:10.1017/S0033291708004807

[20] Ruscio, A.M., Chiu, W.T., Roy-Byrne, P., Stang, P.E., Stein, D.J. and Wittchen, H.U. (2007) Broadening the definition of generalized anxiety disorder: Effects on prevalence and associations with other disorders in the National Comorbidity Survey Replication. Journal of Anxiety Disorders, 21, 662-676. doi:10.1016/j.janxdis.2006.10.004

[21] Carter, R.M., Wittchen, H.U., Pfister, H. and Kessler, R.C. (2001) One-year prevalence of subthreshold and threshold DSM-IV generalized anxiety disorder in a nationally representative sample. Depression and Anxiety, 13, 78-88. doi: $10.1002 /$ da. 1020

[22] Lee, S., Ma, Y.L., Tsang, A. and Kwok, K. (2009) Generalized anxiety disorder with and without excessive worry in Hong Kong. Depression and Anxiety, 26, 956961. doi: $10.1002 /$ da. 20578

[23] Lee, S., Tsang, A., Ruscio, A.M., Haro, J.M., Stein, D.J., Alonso, J., Angermeyer, M.C., Bromet, E.J., Demyttenaere, K., de Girolamo, G., de Graaf, R., Gureje, O., Iwata, N., Karam, E.G., Lepine, J.P., Levinson, D., MedinaMora, M.E., Oakley-Browne, M.A., Posada-Villa, J. and Kessler, R.C. (2009) Implications of modifying the duration requirement of generalized anxiety disorder in developed and developing countries. Psychological Medicine, 39, 1163-1176. doi:10.1017/S0033291708004807

[24] Ruscio, A.M., Lane, M., Roy-Byrne, P., Stang, P.E., Stein, D.J., Wittchen, H.U. and Kessler, R.C. (2005) Should ex- cessive worry be required for a diagnosis of generalized anxiety disorder? Results from the US National Comorbidity Survey Replication. Psychological Medicine, 35, 1761-1772. doi:10.1017/S0033291705005908

[25] Ruscio A.M. (2002) Delimiting the boundaries of generalized anxiety disorder: Differentiating high worriers with and without GAD. Journal of Anxiety Disorders, 16, 377400. doi:10.1016/S0887-6185(02)00130-5

[26] Álvarez, E., Carrasco, J.L., Olivares, J.M., Vilardaga, I., López-Gómez, V. and Pérez, M. (2012) Broadening of generalized anxiety disorders definition does not affect the response to psychiatric care: Findings from the observational ADAN study. Clinical Practice \& Epidemiology in Mental Health, 8, 158-168. doi:10.2174/1745017901208010158

[27] Lobo, A., Chamorro, L., Luque, A., Dal-Ré, R., Badia, X. and Baró, E. (2002) [Validation of the Spanish versions of the Montgomery-Asberg depression and Hamilton anxiety rating scales]. Medicina Clinica, 118, 493-499.

[28] Consejo General de Colegios Oficiales de Farmacéuticos (2008) Catálogo de especialidades farmacéuticas. Consejo General de Colegios Oficiales de Farmacéuticos, Madrid.

[29] Oblikue (2008) eSALUD. Base de datos de costes sanitarios. In: Social, S.C.d.E.e.E.d.1.S.y.P., Ed., SOIKOS, Barcelona.

[30] Kazis, L.E., Anderson, J.J. and Meenan, R.F. (1989) Effect sizes for interpreting changes in health status. Medical Care, 27, S178-S189. doi:10.1097/00005650-198903001-00015

[31] Marciniak, M.D., Lage, M.J., Dunayevich, E., Russell, J.M., Bowman, L., Landbloom, R.P., et al. (2005) The cost of treating anxiety: The medical and demographic correlates that impact total medical costs. Depression and Anxiety, 21, 178-184. doi:10.1002/da.20074

[32] Olfson, M. and Gameroff, M.J. (2007) Generalized anxiety disorder, somatic pain and health care costs. General Hospital Psychiatry, 29, 310-316. doi:10.1016/j.genhosppsych.2007.04.004

[33] Sicras-Mainar, A., Blanca-Tamayo, M., Navarro-Artieda, R. and Rejas-Gutierrez, J. (2009) Use of resources and costs profile in patients with fibromyalgia or generalized anxiety disorder in primary care settings. Atención Primaria, 41, 77-84. doi:10.1016/j.aprim.2008.09.008

[34] Smit, F., Cuijpers, P., Oostenbrink, J., Batelaan, N., de Graaf, R. and Beekman, A. (2006) Costs of nine common mental disorders: Implications for curative and preventive psychiatry. Journal of Mental Health Policy and Economics, 9, 193-200.

[35] Konnopka, A., Leichsenring, F., Leibing, E. and Konig, H.H. (2009) Cost-of-illness studies and cost-effectiveness analyses in anxiety disorders: a systematic review. Journal of Affective Disorders, 114, 14-31. doi:10.1016/j.jad.2008.07.014

[36] Lothgren, M. (2004) Economic evidence in anxiety disorders: A review. European Journal of Health Economics, 5, S20-S25. doi:10.1007/s10198-005-0284-3

[37] Souêtre, E., Lozet, H., Cimarosti, I., Martin, P., Chignon, J.M., Adès, J., et al. (1994) Cost of anxiety disorders: 
impact of comorbidity. Journal of Psychosomatic Research, 38, 151-160. doi:10.1016/0022-3999(94)90145-7

[38] Issakidis, C., Sanderson, K., Corry, J., Andrews, G. and Lapsley, H. (2004) Modelling the population cost-effectiveness of current and evidence-based optimal treatment for anxiety disorders. Psychological Medicine, 34, 19-35. doi:10.1017/S003329170300881X

[39] Bandelow, B., Zohar, J., Hollander, E., Kasper, S., Möller, H.J., WFSBP Task Force on Treatment Guidelines for Anxiety, Obsessive-Compulsive and Post-Traumatic Stress Disorders, Zohar, J., Hollander, E., Kasper, S., Möller, H.J., Bandelow, B., Allgulander, C., Ayuso-Gutierrez, J.,
Baldwin, D.S., Buenvicius, R., Cassano, G., Fineberg, N., Gabriels, L., Hindmarch, I., Kaiya, H., Klein, D.F., Lader, M., Lecrubier, Y., Lépine, J.P., Liebowitz, M.R., LopezIbor, J.J., Marazziti, D., Miguel, E.C., Oh, K.S., Preter, M., Rupprecht, R., Sato, M., Starcevic, V., Stein, D.J., van Ameringen, M. and Vega, J. (2008) World federation of societies of biological psychiatry (WFSBP) guidelines for the pharmacological treatment of anxiety, obsessivecompulsive and post-traumatic stress disorders-First revision. World Journal of Biological Psychiatry, 9, 248312. doi:10.1080/15622970802465807 